\title{
Türkiye'de Muhasebe Meslek Mensuplarının Bireysel Girişimcilik Yönelimi Araştırması
}

\author{
Burak Özdoğan ${ }^{1}$
}

Türkiye'de Muhasebe Meslek Mensuplarının Bireysel Girişimcilik Yönelimi Araştırması

Öz

Yüzyıllardır tüm değişimlere uyum sağlamayı başaran muhasebe mesleği ve meslek mensupları, içinde yaşadığımız yüzyılın en temel gerçekliği haline gelen dijitalleşme ve beraberinde gelişen girişimcilik kültüründen yoğun biçimde etkilenmektedir. Meslek mensuplarının, muhasebeciliğin geleceğinde söz sahibi olabilmesi için bu değişime ayak uydurması ve geleneksel SMMM ya da büro sahibi rolünü teknoloji merkezli girişimci rolüyle değiştirmesi gerekmektedir. Bu çalışma ile Türkiye'de muhasebe meslek mensuplarının bireysel girişimcilik yönelimlerinin tespiti amaçlanmıştır. 393 meslek mensubunun yanıtladığı anket sonuçlarına göre Türkiye'deki meslek mensuplarının bireysel girişimcilik yöneliminin yüksek olduğu tespit edilmiştir. Ayrıca, girişimci olma niyeti yüksek meslek mensuplarının bireysel girişimcilik yönelimi, girişimci olma niyeti düşük olan meslek mensuplarına göre daha yüksek olarak ölçülmüştür.

Anahtar Kelimeler: Muhasebe Mesleği, Bireysel Girişimcilik Yönelimi, Muhasebeci
Research of Individual Entrepreneurial Orientation of Accounting Professionals In Turkey

\section{Abstract}

For centuries, accounting profession and accounting professionals who have managed to adapt to all changes are heavily influenced by digitization and developing entrepreneurship culture that has become the most fundamental reality of the century today. In order for professionals to have a say in the future of accountancy, it is necessary to adapt to this change and replace the role of the traditional CPA or accounting office owner with the role of technology-centric entrepreneur. The aim of this study is to determine the level of individual entrepreneurial orientation of accounting professionals in Turkey. According to the survey results of the 393 accounting professionals, the individual entrepreneurial orientation of the accountants in Turkey has been determined to be high. In addition, the individual entrepreneurial orientation level is measured as high in accountants with the intention of being an entrepreneur while individual entrepreneurial orientation level is measured low when the intention of accountant to be an entrepreneur is low.

Keywords: Accounting Profession, Individual Entrepreneurial Orientation, Accountant

\section{Giriş}

İçinde bulunduğumuz dönemde iş ve onun yapılış biçimi; toplumsal açıdan anlamına, temel motivasyonlarına ve ekonomik yapısına dair bir paradigma değişimi içerisindedir. Bu paradigma değişiminde rol oynayan temel faktörler arasında, geçtiğimiz dönemin sürükleyici gücü olan kurumsal şirketler öncülüğündeki ideal işletme yapısının yerini Start-Up'lara bırakmış olması ve bu devir teslimin beraberinde teknolojinin de desteğiyle paylaşım ekonomisinden bulut bilişime yeni nesil iş modellerini ekonomik yapıya aktif biçimde kazandırması gösterilebilir. Muhasebe mesleği ve meslek mensupları, sahip oldukları bilgi birikimi ve tecrübeleriyle girişimcilerin iş fikirlerini hayata geçirirken ve büyürken en büyük destekçileri olarak görülmektedir. Oysaki gerek sahip oldukları tecrübe gerekse üst düzey muhasebe finans bilgileri ve mesleğin doğası gereği muhasebeciler aslında doğal girişimci adayları olarak görülmelidir. Birçok meslek mensubu, kendi ofisini açarak şirketlerin muhasebe operasyonlarını yürütmekte ve yasal düzenlemelerden işletme yönetimine çok çeşitli konularda danışmanlık hizmeti sunmaktadır.

Tüm dünyada teknolojiden de destek alınarak yeni nesil muhasebe girişimleri kurulmakta ve bu yeni nesil girişimlerin birçoğu sanılanın aksine muhasebe meslek mensupları tarafından

\footnotetext{
${ }^{1}$ Dr. Öğr. Üyesi, Manisa Celal Bayar Üniversitesi iiBF, İşletme Bölümü, burak.ozdogan@cbu.edu.tr, Yazar ORCID bilgisi: https://orcid.org/0000-0002-8504-5085
} 
değil, meslekle ilişkisi olmayan farklı uzmanlıklardaki girişimciler tarafından kurulmaktadır. Bu yapıların çoğunda hemen hemen hiç meslek mensubu çalışmamaktadır (Özdoğan, 2017). Ancak yukarıda da belirtildiği üzere, muhasebe meslek mensupları, teknik donanım ve nitelik bakımından bir girişimi kurup büyütebilecek yeterliliğe sahiptir. Bu noktada meslek mensuplarının bireysel girişimcilik yönelimi (Individual Entrepreneurial Orientation - IEO), önemli bir gösterge olarak meslek mensuplarının geleceğin iş modellerine uyum sağlama yetenekleri hakkında önemli ipuçları sağlayabilecektir. Yüksek bireysel girişimcilik yönelimi, bireylerin girişimci olma ihtimallerini ve belirsiz çevre koşullarında başarılı olma intimallerini artırmaktadır. Bu kapsamda, bireysel girişimcilik yöneliminin ölçülerek düşükse nasıl yükseltilebileceğine veya yüksek girişimcilik yöneliminin nasıl desteklenebileceğine dair yol haritası oluşturmak önemlidir.

Bu çalışma ile Türkiye'de muhasebe meslek mensuplarının girişimcilik yönelimlerinin tespit edilmesi amaçlanmıştır. Bu çerçevede öncelikle mesleğin dönüşümü ele alınmış sonrasında bireysel girişimcilik yönelimi kavramına yönelik teorik çerçeve çizilmiştir. Çalışmanın dördüncü bölümünde Türkiye'de muhasebe meslek mensuplarının bireysel girişimcilik yönelimini ölçmeye yönelik gerçekleştirilen anket uygulaması ve hipotez testleri gerçekleştirilmiştir.

\section{Muhasebenin Geleceği ve Meslek Mensuplarının Dönüşen Rolleri}

Muhasebe mesleği; antik dönemlere dayanan köklü geçmiş̧i (Brown, 2014: 16) ve değişime ayak uydurabilme, gerekli dönüşümleri zamanında gerçekleştirebilme ve güncel işletme sorunlarına çözüm sunabilme yetenekleriyle daima güncelliğini koruyan önemli bir meslek ve bilim dalıdır. Venedikli tüccarların çift taraflı kayıt sistemini uygulamasından çok önce, ilkel muhasebe olarak da adlandırılan tek taraflı kayıt sistemleriyle defterler tutuluyor, hesaplar kapatılamıyor ve dolayısıyla işletmeler doğru verilerle yönetilemiyordu (Lauwers ve Willekens, 1994). Pacioli'nin Summa de Aritmetica kitabında çift taraflı kayıt sisteminin çerçevesini çizdikten sonra hesaplar birbirleriyle ilişkilendirilebilir, kapatılabilir ve tutarlı veriler elde edilebilir hale dönüştü (Lee, vd., 2014). On sekizinci Yüzyıla kadar muhasebeden beklenen işletme sahiplerine ve kamuya kar veya zarara yönelik bilgi vermesi iken özellikle İngiltere'de ortak hisseli şirket kavramının geliştirilmesiyle birlikte işletmenin sürekliliği, hissedarların sınırlı sorumluluğu ve hisselerin devri gibi yeni gelişmeler şirket kavramı içerisinde toplanmıştır. Hisselerin devredilebilmesi, hisse alım satımının gerçekleştiği piyasanın ortaya çıkmasını ve dolayısıyla şirketlerin finansal bilgilerine ihtiyaç duyan işletme dışı bir yatırımcı grubunun ortaya çıkmasını sağlamıştır (Scott, 1997).

Modern işletmelerin ve içerisinde bulundukları çevrenin değişen yapısı, bir paydaş olarak muhasebeden beklentileri de farklılaştırmış ve meslek mensuplarının işletme defterlerinin tutulması, finansal tabloların hazırlanması ve diğer temel görevlerin yanı sıra uzun yıllardır stratejik yönetim danışmanlığı rolünü de meslek mensuplarına yüklemiştir (Holtzman, 2004). Bugün, dünya genelinde iş modelleri ve iş yapış biçimleri yeni bir dönüşüm süreci içerisinden geçmekte ve geleneksel köklü kurumsal şirketlerin karşısına birçok alanda gücünü teknolojiden alan girişimci şirketleri çıkmaktadır. Start-Up olarak anılan bu yeni girişimler, kurumsal şirketlere alternatif olarak çok çeşitli sektörde faaliyet göstermekte ve ağırlıklı olarak az sayıda kurucu ekip ve çalışanla, esnek ve çevik bir yönetim anlayışıyla idare edilmektedir. Start-Up kavramının tam olarak Türkçe karşılığı bulunmamakla birlikte tanımlaması şu şekildedir; "Yeni kurulmuş, hızlı büyüme potansiyeli bulunan ancak yeterli finansal kaynaklara sahip olmayan, yüksek risk ve getiri potansiyeline sahip girişimdir" (Özdoğan, 2018: 34). Birçok farklı alanda kurulan StartUp'ların ortak özelliği ise muhasebe fonksiyonuna duydukları intiyaçtır. Az sayıda çalışanla iş yapmaları ve farklı uzmanlıklara sahip olmaları sebebiyle birçok girişimin kuruluş ve büyüme 
aşamasında en büyük destekçisi muhasebe meslek mensupları olmaktadır. Muhasebe meslek mensupları bu girişimlerin sadece kuruluş ve diğer muhasebe kayıt süreçlerini üstlenmemekte aynı zamanda bir mentor ya da danışman rolüyle işletmeyi büyütecek adımlar atılabilmesine destek olmaktadır.

Diğer taraftan iletişim teknolojilerindeki değişimler birçok mesleği etkilediği gibi muhasebe mesleğini de doğrudan etkilemektedir. Uluslararası Muhasebeciler Federasyonu (IFAC) 2017 yıIında yayımladığı raporda; yakın gelecekte muhasebecilerin bulut bilişim, yapay zekâ ve büyük veri ve blok zinciri gibi gelişmiş teknolojileri entegre biçimde kullanması gerekeceğini belirterek meslek mensuplarının hızla bu ve benzeri gelişmelere uyum sağlaması gerekliliğini belirtmiş ve muhasebe eğitiminin bu yönde revize edilmesi gerektiğini vurgulamıştır (Islam, 2017). Özellikle denetim şirketleri, bu teknolojilerin kullanımına önemli ölçüde yatırım yapmakta ve süreçlerini bu doğrultuda revize etmektedir (Lowe, vd. 2017). Ancak sadece denetim şirketlerinin değil, irili ufaklı muhasebe ofisleri ve birçok kurumda yer alan muhasebe birimlerinin de bu dönüşüme hazırlıklı olması gerekmektedir (Tysiac ve Drew 2018). Yine IFAC'ın 2015 ve 2016 yıllarında gerçekleştirdiği küçük ve orta ölçekli muhasebe ofislerine yönelik anket çalışmasının sonuçlarına göre muhasebeciler; yeni müşteri geliştirmede, mevcut yetenekli insan kaynağını koruma ve yenilerini elde etmede, yasal düzenlemelere uyum sağlamada ve teknolojik gelişmelere uyum sağlamada ciddi problemler yaşamaktadır (IFAC, 2016). Dolayısıyla muhasebe meslek mensupları bir yandan dünya genelinde hızla benimsenen Start-Up odaklı iş yapış biçimine adapte olmalı diğer yandan mevcut yetkinlikleri arasına yeni teknolojilerin kullanımını ve bu teknolojilerin kullanımıyla ortaya çıkan yeni veri yapısını analiz edebilmeyi eklemesi gerekmektedir.

\section{Bireysel Girişimcilik Yönelimi Kavramı ve Muhasebe Mesleği Mensupları}

Girişimcilik yönelimi kavramı (entrepreneurial orientation), yeni bir girişime yol açan süreçler, uygulamalar ve karar verme faaliyetlerini ifade etmektedir (Lumpkin ve Dess, 1996:136). Rauch vd. (2009:762), girişimcilik yönelimi kavramını "organizasyonlara girişimsel kararlarda ve uygulamalarda temel teşkil edecek strateji üretme süreci" olarak tanımlamıştır. Miller (1983) ve Covin ve Slevin (1986), kurumsal yapılar için kullanılan girişimcilik yöneliminin; yenilikçilik, proaktiflik ve risk alma, otonomi ve rekabetçi agresiflik şeklinde beş bileşenden oluştuğunu belirtmektedir. Yapılan çalışmalar, girişimcilik yönelimi ile işletme performansının pozitif ilişkili olduğu sonucunu ortaya koymuştur (Lumpkin ve Dess, 1996; Wiklund ve Shepherd 2003; Rauch ve Frese, 2009). Dolayısıyla girişimcilik yönelimi, işletmelerin girişimcilik faaliyetlerinin sonuçlarına yönelik önemli bir gösterge olarak kabul edilmiştir (Covin ve Slevin, 1991). Daha yüksek girişimcilik yönelimine sahip şirketlerin pazara yeni ürünler sunma, faaliyetlerini çeşitlendirme ve belirsiz çevre koşulları altında başarılı olmaları daha muhtemeldir (Alayo, vd., 2019).

Araştırmacılar, şirketlerin girişimciliğe yatkınlıklarını ölçmek için kullanılan girişimcilik yönelimi kavramını bireyler için de kullanmak üzere çalışmalar gerçekleştirmiştir (Robinson vd. 1991; Bolton ve Lane, 2012; Koe, 2016). Tıpkı kurumlardaki gibi, bireylerde de yüksek girişimcilik yönelimi, kişilerin geleceğe yönelik hazırlıklı olma seviyesini artıracak, yeniliklere daha açık olmaları anlamına gelebilecektir. Yapılan bilimsel çalışmalar, bu görüşü destekleyen sonuçlara ulaşmıştır. Bolton ve Lane (2012), güçlü bireysel girişimcilik yönelimine sahip olmanın kişileri girişimciliğe sevk edeceğini savunmaktadır. Chien (2014), 99 kişiyle yaptığı çalışma sonucunda bireysel girişimcilik yönelimi ile işletme performansı arasında pozitif ilişki olduğunu savunmaktadır. Yine Bolton (2012) tarafından 340 katılımcıyla gerçekleştirilen araştırma sonuçlarına göre bireysel girişimcilik yönelimi ile girişimcilerin işletme başarısının pozitif ilişkili olduğu ortaya kon- 
muştur. Koe (2016), çalışmasında bireysel girişimcilik yönelimi ile girişimci olma niyeti arasındaki ilişkiyi inceleme konusu yapmış ve sonuç olarak yüksek bireysel girişimcilik yöneliminin kişilerin girişimci olmalarında pozitif etkili olduğunu savunmuştur.

Bolton ve Lane (2012), çalışmalarında bireysel girişimcilik yöneliminin üç boyutu olduğunu belirtmektedir. Bu boyutlar; risk alma, proaktiflik ve yenilikçilik boyutlarıdır. Bu boyutlar şu şekilde açıklanabilir (Bolton ve Lane, 2012);

-Risk Alma Boyutu: Bilinmeyen, yüksek sorumluluk gerektiren ve önemli derecede kaynağın kullanılması gereken belirsiz çevre koşullarında faaliyet göstermeye isteklilik olarak tanımlanmaktadır.

- Proaktiflik: Fırsatları gözleyerek, rekabetin ötesine geçip uzgörü çerçevesinde yeni ürün ve hizmetlerin belirlenmesi, gelecek talep doğrultusunda hareket edebilmek olarak tanımlanmaktadır.

- Yenilikçilik: Yeni ürün ve hizmetlerin sunulması yoluyla yaratıcılığa ve deneyselliğe yatkınIığın yanı sıra araştırma ve geliştirme faaliyetleri neticesinde teknolojik liderliği ifade etmektedir.

Muhasebe meslek mensuplarının güçlü bireysel girişimcilik yönelimine sahip olması, mesleğin geleceğine yönelik beklentileri karşılayabilmelerine ve yakın gelecekte girişimcilerin de içerisinde yer alacağı rekabet çevresinde hayatta kalabilmelerine imkân tanıyacaktır. Önceki bölümde değinilen Start-Up'lar, bir taraftan belirtildiği üzere muhasebecilere büyük bir ihtiyaç duyarken diğer taraftan önemli bir pazar olarak gördükleri muhasebe teknolojileri aracılığıyla muhasebe meslek mensuplarıyla rekabet etmeye başlamaktadır. Bugün hayata geçirilen birçok muhasebe Start-Up'ında ya hiç muhasebe meslek mensubu bulunmamakta ya da çok az sayıda bulunmaktadır (Özdoğan, 2017). Bu rekabetle başa çıkabilmesi için muhasebe meslek mensuplarının da yeni teknolojilere hızla uyum sağlayarak kendi girişimlerini kurmaları ve Start-Up'lar arasındaki yerlerini almaları gerekmektedir. Özünde muhasebe meslek mensupları, sahip oldukları teknik yetkinlikler ve teknik olmayan yetkinlikler sayesinde başarılı bir şekilde işletme kurabilecek ve yönetebilecek donanımdadır. Dünya genelinde mesleğin gelişimi için çalışan mesleki sivil toplum yapıları, gelişmekte olan bu yeni rekabetçi çevreyi öngörmekte ve çeşitli çalışmalarla meslek mensuplarının yeni koşullara adaptasyonunu sağlamayı amaçlamaktadır. IFAC gibi muhasebe meslek örgütleri, yayımladıkları Eğitim Standartları eliyle muhasebe meslek mensuplarının sahip olması gereken yetkinlikleri dünya genelinde standartlaştırmaya çalışmakta ve dolayısıyla önemli bir temel teşkil etmektedir (IFAC, 2018). Mevcut Start-Up kültürünü muhasebe meslek mensuplarının avantajına çevirmeyi amaçlayan Amerikan Serbest Muhasebeciler Enstitüsü (AICPA), CPA.com ile iş birliğine giderek muhasebe meslek mensuplarının yenilikçi muhasebe fikirlerini birer girişime dönüştürmelerini sağlayabilmek adına girişim hızlandırma programı başlatmıştır. ${ }^{2}$

Muhasebe meslek mensuplarının yetkinliklerini yeni teknolojilerle birleştirerek birer girişimciye dönüşmeleri, gelecekteki fırsatları yakalamalarını ve mesleğin bir sonraki dönüşümüne kadar hayatta kalmalarını sağlayacaktır. Ancak bir girişimci olabilmek için sadece yetkinlikler ve iyi bir iş fikri yeterli olmamaktadır. Girişimcinin fikirlerini hayata geçirecek riskleri alması gerekmektedir. Yapılan çeşitli bilimsel çalışmalarda muhasebe meslek mensuplarının risk algısının düşük olduğu (Helliar, vd., 2002) ve riskten kaçınma seviyesinin yüksek olduğu (Hoitash, vd., 2016)

\footnotetext{
${ }^{2}$ Bknz: https://www.aicpa-cima.com/accelerator.html
} 
sonucuna ulaşılmıştır. Bu noktada bireysel girişimcilik yönelimi, meslek mensupları açısından önemli bir gösterge niteliği taşımaktadır.

\section{Meslek Mensuplarının Bireysel Girişimcilik Yönelimi Araştırması}

Muhasebe meslek mensuplarının, dijitalleşmeyle birlikte mesleğin geleneksel icrasını tehdit eden dönüşümüne uyum sağlayabilmeleri ve mesleğin geleceğinde öncü rol üstlenebilmeleri için girişimciliğin rolü ve önemi önceki kısımlarda detaylandırılmıştır. Bu çalışma ile Türkiye'de muhasebe meslek mensuplarının bireysel girişimcilik yönelimleri araştırma konusu yapılmıştır. Yüksek bireysel girişimcilik yöneliminin kişilerin girişimci olmalarında önemli bir payı olduğu ortaya konmuştu. Bu kapsamda çalışma ile hem Türkiye'deki meslek mensuplarının girişimcilik yönelimi seviyesi hem de varsa girişimcilik yönelimlerindeki farklılıklar ve bu farklılıkların nedenleri ele alınmıştır. Dolayısıyla çalışma kapsamında temel itibariyle şu üç araştırma problemi tanımlanmıştır:

- Muhasebe meslek mensuplarının bireysel girişimcilik yönelimleri yüksek mi?

- Demografik değişkenler, muhasebe meslek mensuplarının bireysel girişimcilik yönelimi düzeylerini etkiliyor mu?

- Girişimci olma niyetine sahip muhasebe meslek mensupları ile böyle bir isteği olmayanların bireysel girişimcilik yönelim seviyeleri arasında bir farklılık var mı?

Çalışmanın önceki bölümlerinde de detaylandırılan literatür bağlamında, bu araştırmada test edilmek üzere 7 adet hipotez geliştirilmiştir. Geliştirilen hipotezler şu şekildedir;

H1a: Muhasebe meslek mensuplarının bireysel girişimcilik yönelimleri yüksektir.

H1b: Kadın ve erkek muhasebe meslek mensuplarının bireysel girişimcilik yönelimleri arasında fark vardır.

H1c: Kendi SMM ofisinde çalışan ve diğer kurumlarda çalışan muhasebe meslek mensuplarının bireysel girişimcilik yönelimleri arasında fark vardır.

H1d: Yaş grupları açısından 30 yaş altı ile 30 yaş üstü muhasebe meslek mensuplarının bireysel girişimcilik yönelimleri arasında fark vardır.

H1e: Staj aşamasında bulunanlar ile SMMM belgesine sahip muhasebe meslek mensuplarının bireysel girişimcilik yönelimleri arasında fark vardır.

H1f: Lisans ve yüksek lisans eğitimi almış muhasebe meslek mensuplarının bireysel girişimcilik yönelimleri arasında fark vardır.

H1g: Girişimci olma niyeti yüksek muhasebe meslek mensupları ile olmayan muhasebe meslek mensuplarının bireysel girişimcilik yönelimi boyutları arasında farklııı vardır.

Araştırmada hipotezler çerçevesinde geliştirilen araştırma modeli Şekil 1'de gösterilmektedir; 


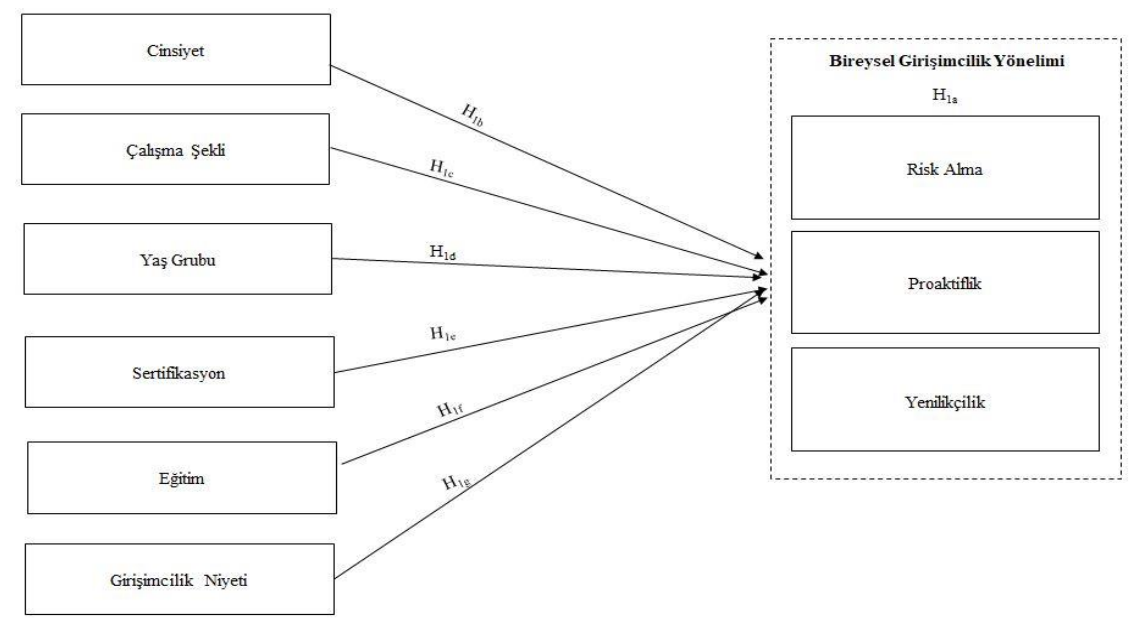

Şekil 1: Araştırma Modeli

\subsection{Araştırma Metodolojisi}

Araştırma sorularının yanıtlanabilmesi amacıyla bu çalışmada anket yöntemi kullanılmıştır. Anketin ilk bölümünde kapalı uçlu, diğer bölümünde ise beşli Likert ölçeğinde hazırlanan sorulara yer verilmiştir. Anketin ilk bölümünde yanıtlayıcıların demografik özelliklerinin ve mesleki seviyelerinin anlaşılmasına yönelik sorular yer almıştır. İkinci bölümünde ise araştırmaya katılan muhasebe meslek mensuplarının girişimcilik yönelimlerini ölçmeye yönelik sorular bulunmaktadır. Anketin ikinci bölümünde kullanılacak soru formunun oluşturulmasında Bolton ve Lane (2012) tarafından geliştirilen Bireysel Girişimcilik Yönelimi ölçeğinden yararlanılmıştır. Ölçek; yenilikçilik, risk ve proaktiflik olmak üzere toplam üç boyuttan ve 10 ifadeden oluşmaktadır. Soru formuna, proaktiflik boyutuna 2 adet ve yenilikçilik boyutuna 1 adet olmak üzere Robinson vd. (1991) tarafından hazırlanan ölçekten 3 adet ifade soru formuna eklenmiştir. Formda, bireysel girişimcilik yönelimi ölçeğine ilişkin yer alan 10 ifadenin yanı sıra, girişimcilik niyetini ölçmek için Koe (2016) tarafından hazırlanan ölçekten 2 adet ifade eklenmiştir. Bu iki soruya verilen yanıtların puanları toplanarak katılımcılar girişimcilik niyeti düşük ve yüksek olmak üzere iki gruba ayrılmıştır. Her iki soru da $5^{\prime}$ li Likert ölçekle oluşturulmuştur, analiz aşamasında değişken oluşturulurken 2-6 puanları arası birinci grup 6,01-10 puanları arası ikinci grup olarak kodlanmıştır. Soru formunda yaş, cinsiyet, eğitim durumu, tecrübe gibi farklı tanımlayıcı sorular da bulunmaktadır. Form toplam 15 ifadeden oluşmaktadır.

Araştırmanın evrenini Türkiye'de çalışmakta olan muhasebe meslek mensupları oluşturmaktadır. Araştırmanın evren büyüklügü̈ bilinmediğinden olasılıklı olmayan örnekleme yöntemlerinden kolayda örnekleme yöntemi tercih edilmiştir. Ankete katılacak muhasebe meslek mensuplarına, farklı meslek ve sektörlerden iş dünyası profesyonelleri tarafından yaygın biçimde kullanılan çevrim içi bir sosyal ağ olan Linkedın üzerinden ulaşılmıştır. Anket formu, internet ortamında 22 Ekim 2018 - 27 Ekim 2018 tarihleri arasında toplamda 686 muhasebe meslek mensubu ile paylaşılmış ve 516 yanıtlanmış forma ulaşılmıştır. Geri dönüş oranı \%75,2 olarak tespit edilmiştir. Analiz aşamasında 123 adet anket formu eksik yanıt ve diğer farklı hatalar sebebiyle değerlendirmeye alınmamıştır. Sonuç olarak 393 anket formu analize dâhil edilmiştir. 


\subsection{Bulgular}

Çalışmada öncelikle katıımcıların çeşitli yönlerden sınıflandırılmasını sağlayacak tanımlayıcı değişkenler frekans analizi eliyle incelenmiştir. Tablo 1'de bütün halinde görülen istatistikler detaylı incelendiğinde; analize dâhil edilen katılımcıların $163^{\prime} u ̈$ (\%41,5) kadın ve 230 'u $(\% 58,5)$ erkek olduğu görülmektedir. Katılımcıların yaş grubu 18 ile 60 üstü arasında değişmekle birlikte \%90'ı 45 yaş altı katılımcılardan oluşmaktadır. Katılımcıların tamamına yakını $(\% 99,5)$ en az lisans düzeyinde eğitim seviyesine sahiptir. Anket katılımcılarının \%26,9'u SMMM staj aşamasında iken \%73,1'i SMMM belgesine sahip meslek mensuplarından oluşmaktadır. Tecrübe bakımından da katılımcıların 10 yıl altı ve 10 yıl üstü tecrübe açısından hemen hemen ikiye ayrıldıkları söylenebilir. 10 yıldan fazla tecrübeye sahip $\% 47,8^{\prime}$ lik katılımcı grubuna karşılık tecrübesi 5 yıldan az olanlar \%23,4'lük bir payı temsil etmektedir.

Tablo 1: Tanımlayıc Istatistikler

\begin{tabular}{|c|c|c|c|}
\hline $\mathrm{N}=393$ & Gruplar & Frekans & Yüzde \\
\hline \multirow[t]{2}{*}{ Cinsiyet } & Kadın & 163 & 41,5 \\
\hline & Erkek & 230 & 58,5 \\
\hline \multirow[t]{3}{*}{ Yaş } & $18-30$ & 127 & 32,3 \\
\hline & $30-45$ & 227 & 57,8 \\
\hline & 45 üstü & 39 & 9,9 \\
\hline \multirow[t]{2}{*}{ Eğitim } & Lisans & 261 & 66,8 \\
\hline & Lisansüstü & 130 & 33,2 \\
\hline \multirow[t]{3}{*}{ Tecrübe } & 5 yıldan az & 92 & 23,4 \\
\hline & $5-10$ yıl & 113 & 28,8 \\
\hline & 10 yıldan fazla & 188 & 47,8 \\
\hline \multirow[t]{4}{*}{ Çalışma Şekli } & Çalışmıyorum & 35 & 9,4 \\
\hline & Özel Sektör & 250 & 66,8 \\
\hline & Muhasebe Şirketinde Çalışan & 15 & 4,0 \\
\hline & Muhasebe Şirketi Sahibi & 74 & 19,8 \\
\hline \multirow[t]{2}{*}{ Sertifikasyon } & SMMM Stajyer & 105 & 26,9 \\
\hline & SMMM & 286 & 73,1 \\
\hline
\end{tabular}

Araştırma sorularının yanıtlanabilmesi amacıyla analiz sürecinde öncelikle frekans analizi ve ardından boyutlar için açıklayıcı faktör analizi yapılmıştır. Sonrasında hipotez testleri için t testi ve ANOVA analizlerinden yararlanılmıştır. Analizde öncelikle KMO ve Barlett's test sonuçları alınmıştır. KMO test istatistiği bir örneklemin her bir değişken için ve tüm maddeler için yeterliliğini ölçmektedir. Bu testin 0,5'ten yüksek çıkması gerekmekte ve 1'e yaklaşması istenmektedir (Field 2013;695). KMO test sonucu 0,823 çıkarak faktör analizinin değişkenler için uygun olduğu ortaya konmuştur. Barlett sonucu da anlamlı çıkmış $(0,00<0,05)$ ve değişkenlerin uygun bir faktör analizi için yeterince korelasyona sahip olduğunu göstermektedir. Araştırma ölçeğinin güvenilirliği iç tutarlılık katsayısı Crombach's Alpha ile ölçülmüş ve 13 maddelik ölçeğin tümü için bu değer 0,815 olarak tespit edilmiştir. Bu değer ölçeğin yüksek güvenilirliğe sahip olduğunu ortaya koymaktadır. Oluşturulan üç faktör yapısı varyansın \%55'inden fazlasını açıklamaktadır. Gerçekleştirilen doğrulayıcı faktör analizi sonucundaki faktör yükleri ve güvenilirlik katsayıları Tablo 2'de sunulmuştur. 
Tablo 2: Doğrulayıcı Faktör Analizi ve Güvenilirlik Katsayıları

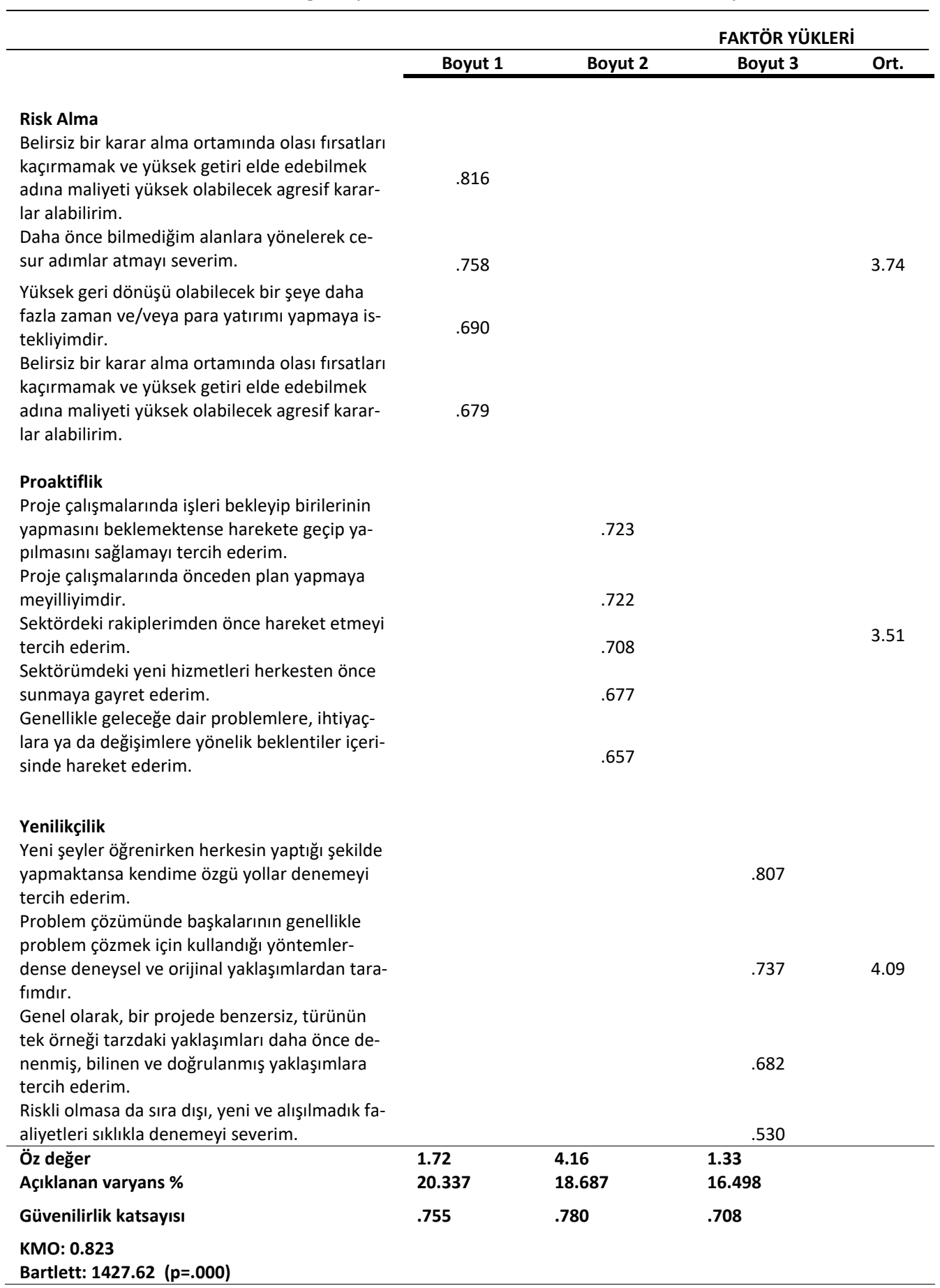


Tablo 2' de belirtilen boyut bazında ortalama puanlar dikkate alındığında araştırmaya katılarak anketi yanıtlayan muhasebe meslek mensuplarının girişimcilik yönelimlerinin yüksek olduğu görülmektedir. Ortalamalar dikkate alındığında 5'li Likert ölçeğinde; 1-2,33 puanları arası değerlerdeki boyutlarda ifadelere katılım düşük, 2,34-3,66 arası puanlarda orta ve 3,66 ve üstü puanlarda ifadelere katılım yüksek olarak değerlendirilmektedir. Bu çerçevede değerlendirildiğinde ölçeğin Risk Alma ve Proaktiflik boyutlarındaki ifadelere yanıtlayıcıların katılım seviyesi yüksek iken Yenilikçilik boyutunda her ne kadar orta sınıfına girse de 3,51 gibi yüksek bir seviye ile ölçülmektedir. Risk alma ve Yenilikçilik boyutlarının Proaktiflik boyutuna göre daha düşük bir ortalamaya sahip olmasının nedenleri arasında, muhasebe mesleğinin doğası gereği meslek mensuplarının riskten korunma eğilimlerinin yüksek olması ve mesleğin uygulamasında kanunlar, standartlar ve diğer düzenlemelerin yoğun biçimde yer alarak yenilikçiliğe yönelik bakış açısını daraltması sayılabilir.

Hipotezlerin test edilmesi için parametrik ve parametrik olmayan hipotez testlerinden hangilerinin kullanılacağını belirlemek amacıyla boyutların basıklık ve çarpıklık değerlerine bakılmıştır. Basıklık ve çarpıklık değerleri $-1+1$ arasında olduğu için verilerin normal dağıldığı kabul edilmiştir (Demir vd., 2016). Bu nedenle hipotez testlerinde parametrik hipotez testleri tercih edilmiştir. Araştırmanın ilk hipotezi olan muhasebe meslek mensuplarının bireysel girişimcilik yönelimi, bulgular neticesinde değerlendirildiğinde yüksek olarak ölçülmüştür. Araştırmaya katılan toplam 393 muhasebe meslek mensubunun bireysel girişimcilik yönelimi ölçeği boyutlarına verdikleri ortalama yanıtlar önceki bölümde değerlendirilmiş ve netice itibariyle sınanan $\mathrm{H} 1 \mathrm{a}$ hipotezi kabul edilmiştir.

Bireysel girişimcilik yöneliminin meslek mensuplarının demografik özellikleri bakımından farklılık gösterebileceği varsayılarak $\mathrm{H} 1 \mathrm{~b}, \mathrm{H} 1 \mathrm{c}, \mathrm{H} 1 \mathrm{~d}$ ve $\mathrm{H} 1 \mathrm{f}$ hipotezleri oluşturulmuştur. Bu çerçevede H1b hipotezi, kadın ve erkek katılımcıların bireysel girişimcilik yönelimlerinin farklılaşacağı yönündedir. Tablo 3'te de görülebileceği üzere, gerçekleştirilen bağımsız örneklem T testi sonucunda katılımcıların cinsiyete göre bireysel girişimcilik yönelimlerinde anlamlı bir farklılığın bulunmadığı tespit edilmiş ve hipotez reddedilmiştir.

Tablo 3: Cinsiyete Göre Katılımcıların Bireysel Girişimcilik Yönelimi

\begin{tabular}{ccccccc}
\hline Boyutlar & Cinsiyet & N & Ortalama & $\begin{array}{c}\text { Standart } \\
\text { Sapma }\end{array}$ & $\begin{array}{c}\text { Standart } \\
\text { Hata Ort. }\end{array}$ & P \\
\hline \multirow{2}{*}{ Yenilikçilik } & Kadın & 163 & 3,7485 &, 66869 &, 05238 & 0,914 \\
& Erkek & 230 & 3,7413 &, 62728 &, 04136 & \\
\multirow{2}{*}{ Risk } & Kadın & 163 & 3,4724 &, 78075 &, 06115 & 0,336 \\
& Erkek & 230 & 3,5478 &, 75337 &, 04968 & \\
\multirow{3}{*}{ Proaktiflik } & Kadın & 163 & 4,0503 &, 63024 &, 04936 & \\
& Erkek & 230 & 4,1122 &, 59233 &, 03906 & 0,321 \\
\hline
\end{tabular}

Araştırmaya katılan muhasebe meslek mensuplarının çalıştıkları yer ve konum itibariyle bireysel girişimcilik yönelimleri arasında farklılık olabileceği varsayımıyla $\mathrm{H} 1 \mathrm{c}$ hipotezi oluşturulmuştur. Tablo 4'te görüldüğü üzere, gerçekleştirilen ANOVA testi sonucunda gruplar arasında istatistiksel açıdan anlamlı bir farklılık olmadığı gözlenmiştir. H1c hipotezi reddedilmiştir. 
Eskişehir Osmangazi Üniversitesi iiBF Dergisi

Tablo 4: Çalışma Şekline Göre Katılımcıların Bireysel Girişimcilik Yönelimi

\begin{tabular}{ccccccc}
\hline & & $\begin{array}{c}\text { Sum of } \\
\text { Squa- } \\
\text { res }\end{array}$ & df & $\begin{array}{c}\text { Mean } \\
\text { Square }\end{array}$ & f & p \\
\hline \multirow{2}{*}{ Yenilikçilik } & Gruplar arası & 1,154 & 3 &, 385 &, 923 &, 430 \\
& Grup içi & 154,279 & 370 &, 417 & & \\
Risk & Gruplar arası & 2,385 & 3 &, 795 & 1,352 &, 257 \\
& Grup içi & 217,604 & 370 &, 588 & &, 085 \\
Proaktiflik & Gruplar arası & 2,479 & 3 &, 826 & 2,228 &, 371 \\
\hline
\end{tabular}

H1d hipotezi, katılımcıların yaş grupları bakımından (18-30, 31-45, 46-60) bireysel girişimcilik yönelimlerinde anlamlı bir farklılık olacağı varsayımı altında kurulmuştur. Tablo 5 'te görüldüğü üzere, ANOVA analizi ile gerçekleştirilen hipotez testi sonucunda gruplar arasında anlamlı bir farklılık olmadığı gözlenerek hipotez reddedilmiştir.

Tablo 5: Yaş Gruplarına Göre Katılımcıların Bireysel Girişimcilik Yönelimi

\begin{tabular}{|c|c|c|c|c|c|c|}
\hline & & $\begin{array}{l}\text { Sum of } \\
\text { Squares }\end{array}$ & df & $\begin{array}{l}\text { Mean } \\
\text { Square }\end{array}$ & $f$ & $p$ \\
\hline \multirow[t]{2}{*}{ Yenilikçilik } & Gruplar arası & 344 & 2 & 172 & ,414 & 662 \\
\hline & Grup içi & 162,206 & 390 & ,416 & & \\
\hline \multirow[t]{2}{*}{ Risk } & Gruplar arası & 1,406 & 2 & 703 & 1,203 & 301 \\
\hline & Grup içi & 227,861 & 390 & ,584 & & \\
\hline \multirow[t]{2}{*}{ Proaktiflik } & Gruplar arası & ,505 & 2 & ,253 & ,682 & ,506 \\
\hline & Grup içi & 144,553 & 390 & 371 & & \\
\hline
\end{tabular}

Henüz staj aşamasında bulunan SMMM adayları ile hâlihazırda SMMM sertifikasyonuna sahip meslek mensuplarının bireysel girişimcilik yönelimleri arasında farklılık olabileceği varsayımıyla oluşturulan $\mathrm{H} 1 \mathrm{~g}$ hipotezi, gerçekleştirilen $\mathrm{T}$ testi analizi sonucunda reddedilmiştir.

Tablo 6: Sertifikasyon Durumuna Göre Bireysel Girişimcilik Yönelimi

\begin{tabular}{ccccccc}
\hline Boyutlar & Sertifika & N & Ortalama & $\begin{array}{c}\text { Standart } \\
\text { Sapma }\end{array}$ & $\begin{array}{c}\text { Standart } \\
\text { Hata Ort. }\end{array}$ & P \\
\hline \multirow{2}{*}{ Yenilikçilik } & Staj Aşaması & 105 & 3,8048 &, 62786 &, 06127 & 0,272 \\
& SMMM & 286 & 3,7238 &, 65105 &, 03850 & 0,202 \\
\multirow{2}{*}{ Risk } & Staj Aşaması & 105 & 3,5857 &, 63153 &, 06163 &, 04776 \\
\multirow{2}{*}{ Proaktiflik } & SMMM & 286 & 3,4860 &, 80773 &, 063 \\
& Staj Aşaması & 105 & 4,0171 &, 64457 &, 06290 &, 183 \\
\hline
\end{tabular}

H1f hipotezinde belirtilen katılımcıların lisans ve lisans üstü eğitim seviyelerine sahip olmasının bireysel girişimcilik yönelimlerinde anlamlı bir farklıığa yol açacağı varsayımı, T testi ile analiz edilmiş ve sonuç olarak her ne kadar lisans eğitim seviyesindeki katılımcıların boyutlara katılım ortalamaları her üç boyut için de daha yüksek olsa da istatistiksel açıdan anlamlı bir farklılık olmadığı gözlenmiştir. H1f hipotezi reddedilmiştir. 
Tablo 7: Eğitim Durumuna Göre Katılımcıların Bireysel Girişimcilik Yönelimi

\begin{tabular}{|c|c|c|c|c|c|c|}
\hline Boyutlar & Eğitim & $\mathbf{N}$ & Ortalama & $\begin{array}{c}\text { Standart } \\
\text { Sapma }\end{array}$ & $\begin{array}{l}\text { Standart } \\
\text { Hata Ort. }\end{array}$ & $\mathbf{P}$ \\
\hline \multirow[b]{2}{*}{ Yenilikçilik } & Lisans & 261 & 3,7672 & 60661 & ,03755 & 0,401 \\
\hline & $\begin{array}{l}\text { Lisans } \\
\text { Üstü }\end{array}$ & 130 & 3,7058 & 71492 & ,06270 & \\
\hline \multirow[b]{2}{*}{ Risk } & Lisans & 261 & 3,5584 & 77191 & 04778 & 0,214 \\
\hline & $\begin{array}{l}\text { Lisans } \\
\text { Üstü }\end{array}$ & 130 & 3,4577 & 71808 & ,06298 & \\
\hline & Lisans & 261 & 4,1142 & 58756 & ,03637 & 0,220 \\
\hline Proaktiflik & $\begin{array}{l}\text { Lisans } \\
\text { Üstü }\end{array}$ & 130 & 4,0338 & 64993 & ,05700 & \\
\hline
\end{tabular}

H1g hipotezi, katılımcılara yöneltilen "Kendim için çalışmak isterim" ve "kendi girişimimi kurmak isterim" ifadeleriyle ölçülen girişimcilik niyeti yüksek olan meslek mensuplarıyla düşük meslek mensuplarının bireysel girişimcilik yönelimi boyutları arasında anlamlı farklıık gözleneceği beklentisiyle oluşturulmuştur. Tablo $8^{\prime}$ de da görülebileceği üzere girişimcilik niyeti düşük ve yüksek olan meslek mensuplarının Yenilikçilik ve Proaktiflik boyutlarına verdikleri yanıtlar anlamı şekilde farklı çıkmıştır. Yani Yenilikçilik ve Proaktiflik boyutları, girişimcilik niyeti yüksek meslek mensuplarında anlamlı biçimde daha yüksek çıkmıştır. Dolayısıyla hipotez kabul edilmiştir.

Tablo 8: Girişimcilik Niyeti ile Bireysel Girişimcilik Yönelimi Boyutları Iliş̧kisi

\begin{tabular}{ccccccc}
\hline Boyutlar & Girişimcilik Niyeti & $\mathbf{N}$ & Ortalama & $\begin{array}{c}\text { Standart } \\
\text { Sapma }\end{array}$ & $\begin{array}{c}\text { Standart Hata } \\
\text { Ort. }\end{array}$ & P \\
\hline \multirow{2}{*}{ Yenilikçilik } & Düşük & 61 & 3,5328 &, 66376 &, 08499 & 0,005 \\
& Yüksek & 332 & 3,7831 &, 63361 &, 03477 & 0,133 \\
\multirow{2}{*}{ Risk } & Düşük & 61 & 3,3811 &, 77407 &, 09911 &, 04180 \\
\multirow{2}{*}{ Proaktiflik } & Yüksek & 332 & 3,5414 &, 76160 &, 09745 & $\underline{0,001}$ \\
\hline
\end{tabular}

\section{Sonuç}

Teknolojinin ve girişimcilik kültürünün birbirine paralel biçimde hızlı gelişimi fırsatları ve tehditleri içerisinde barındıran önemli bir dönüşümü beraberinde getirmiştir. Geleneksel işlerin ve iş yapış biçimlerinin aksayan yönlerini kendilerine hedef alan teknoloji odaklı girişimciler, doğrudan uzmanlıkları olmayan alanlarda dahi yıkıcı bir rekabet yaratmayı başarmaktadır. Muhasebe mesleği ve meslek mensupları da bu hızlı dönüşümden etkilenmekte ve ortaya çıkan yeni nesil muhasebe girişimleri, mesleğin mevcut temsilcilerini tehdit etmekte ve gelecekte mesleğin yapılış biçimini etkileme gücüne sahip olmaktadır. Bu çerçeve dâhilinde, meslek mensuplarının muhasebenin geleceğinde de söz sahibi olabilmesi için kendilerinin de birer girişimci olarak hâlihazırda içerisinde bulundukları yapının aksayan yönlerini fırsata çevirebilecek iş modellerini kurgulaması gerekmektedir. Dolayısıyla muhasebe meslek mensuplarının girişimciliğe yatkınlıkları ve yeni gelişen iş ve rekabet çevresine adaptasyon yetenekleri önem arz etmektedir.

Çalışmada kullanılan bireysel girişimcilik yönelimi; kişilerin yenilikçiliğe, risk almaya ve proaktif davranmaya yatkınlıklarını ortaya koyan bir ölçektir. Yüksek bireysel girişimcilik yönelimi, girişimci olma arzusuyla birleştiğinde başarılı bir girişim için gerekli altyapının mevcudiyetini göstermektedir. Bu kapsamda gerçekleştirilen çalışmada, Türkiye'de muhasebe meslek mensuplarının bireysel girişimcilik yönelimlerinin yüksek olduğu sonucu tespit edilmiştir. Üç boyut 
içerisinde görece en düşük puana sahip boyut olarak proaktiflik tespit edilmiştir. Dolayısıyla meslek mensuplarının bu boyutun gerektirdiği proaktiflik özelliklerinin geliştirilmesi, bireysel girişimcilik yöneliminin daha da artmasına imkân tanıyacaktır. Muhasebe mesleğinin büyük ölçüde standartlar ve çeşitli yasal düzenlemelerle çizilen çerçeve içerisinde yürütülen bir meslek olarak algılanması, meslek mensuplarının geleceğe yönelik daha öngörülü olarak hareket etme, olası değişimleri tahmin etmeye ve bu değişimlere hazırlanmaya çalışma gibi faaliyetleri gerçekleştirmelerine gerek olmadığı şeklinde bir yanılgıya yol açabilir. Ancak çalışmada da özetlenen yeni rekabet koşulları, meslek mensuplarının en fazla geliştirmeleri gereken yönleri arasında proaktif düşünme ve hareket etmenin olduğunu göstermektedir.

Çalışmada diğer taraftan; yaş, cinsiyet, eğitim durumu gibi demografik değişkenlerin meslek mensuplarının girişimcilik yönelimini anlamlı şekilde etkilemediği hipotez testleri ile ortaya konulmuştur. Ayrıca girişimcilik niyeti yüksek meslek mensuplarının bireysel girişimcilik yönelimi de risk boyutu hariç olmak üzere yüksek olarak ölçülmüştür. Bu durum, çalışmada da değinilen Helliar vd. (2002) ve Hoitash vd. (2016) tarafından yapılan çalışma sonuçlarını desteklemektedir. Risk boyutunun görece daha düşük çıkmasının sebebi olarak muhasebe mesleğinin doğası gereği mensuplarının riskten korunma/kaçınma eğiliminde oldukları söylenebilir. Muhasebe meslek mensuplarının bireysel anlamda kendilerini ve işlerini geliştirmek adına girişimci olarak alacakları risk ile işlerini titizlikle yapmak adına sahip oldukları temkinliliği birbirinden ayırmaları gerekmektedir. Yüksek bireysel girişimcilik yöneliminin beklenen etkiye dönüşebilmesi adına risk algısının geliştirilmesi önemlidir.

Araştırma sonuçları göstermektedir ki; Türkiye'de muhasebe meslek mensupları, yüksek bireysel girişimcilik yönelimi ve yüksek girişimcilik niyeti ile mesleğin geleceğinde aktif rol oynayabilecek ve olası iş fırsatlarını değerlendirebilecek karakteristik özelliklere sahiptir. Diğer taraftan bu çalışmada ölçülmeyen ancak gelecek çalışmalar için önemli bir araştırma konusu olabilecek, meslek mensuplarının bugünün ve geleceğin yetkinliklerine ne derece sahip oldukları, yazııım, mobil teknolojiler ve iletişim teknolojileri gibi alanları kullanabilme ve diğer becerilerinin seviyesi de önemli faktörler arasında sayılabilecektir. 


\section{Kaynaklar}

Alayo, Mikel, Maseda, A., Iturralde, T., \& Arzubiaga, U. (2019), “Internationalization and Entrepreneurial Orientation of Family SMEs: The Influence of The Family Character", International Business Review, Vol. 28, No. 1: 48-59.

Bolton, Dawn Langkamp (2012), "Individual Entrepreneurial Orientation: Further Investigation of a Measurement Instrument", Academy of Entrepreneurship Journal, Vol. 18, No. 1: 91.

Bolton, Dawn Langkamp, and Michelle D. Lane (2012), “Individual Entrepreneurial Orientation: Development of a Measurement Instrument", Education + Training, Vol. 54, No.2/3: 219-233.

Brown, Richard (2014), A History of Accounting and Accountants, Routledge, London.

Covin, Jeffrey G., and Dennis P. Slevin (1991), “A Conceptual Model of Entrepreneurship as Firm Behavior", Entrepreneurship Theory and Practice, Vol. 16, No. 1: 7-26.

Demir, Ergül, Özkan Saatçioğlu ve Fatih İmrol (2016), “Uluslararası Dergilerde Yayımlanan Eğitim Araştırmalarının Normallik Varsayımları Açısından İncelenmesi”, Current Research in Education, Vol. 2, No. 3: 130-148.

Field, Andy (2013). Discovering Statistics Using IBM SPSS Statistics (4th ed.). London.

Helliar, Christine V., Lonie, Aalasdair A., Power, D. M., and Sinclair, C. D. (2002), “Managerial Attitudes to Risk: A Comparison of Scottish Chartered Accountants and UK Managers", Journal of International Accounting, Auditing and Taxation, Vol. 11, No. 2, 165-190.

Hoitash, Rani, Udi Hoitash, and Ahmet C. Kurt (2016), “Do Accountants Make Better Chief Financial Officers?”, Journal of Accounting and Economics, Vol. 61, No. 2-3, 414-432.

Holtzman, Yair (2004), "The Transformation of The Accounting Profession in the United States: From Information Processing to Strategic Business Advising", Journal of Management Development, Vol. 23, No. 10: 949-961.

IFAC (2016), "Global SMP Survey 2016", IFAC, http://www.ifac.org/publications-resources/2016-ifac-global-smp-survey-report-summary?utm_source=IFAC+Main+List\&utm_campaign=07d0043b16-EMAIL_CAMPAIGN_2017_03_16\&utm_medium=email\&utm_term=0_cc08d67019-07d0043b16-80401485, (Erişim: 29.10.2018).

IFAC (2018). Handbook of International Education Pronouncements 2017. IFAC, https://www.ifac.org/publications-resources/2017-handbook-international-education-pronouncements, (Erişim: 24.10.2018).

Islam, Muhammad A. (2017), "Future of Accounting Profession: Three Major Changes and Implications for Teaching and Research" Business Reporting, International Federation of Accountants (IFAC).

Koe, Wei-Loon (2016), "The Relationship between Individual Entrepreneurial Orientation (IEO) and Entrepreneurial Intention", Journal of Global Entrepreneurship Research, Vol. 6, No. 1: 13.

Langkamp Bolton, D., and Lane, Michelle D. (2012), “Individual Entrepreneurial Orientation: Development of a Measurement Instrument", Education+ Training, Vol. 54, No. 2/3, 219-233.

Lauwers, Luc, and Marleen Willekens (1994), "Five Hundred Years of Bookkeeping: A Portrait of Luca Pacioli", Tijdschrift voor Economie en Management, Vol. 39, No. 3: 289-304.

Lee, Thomas Alexander, Ashton Bishop, and Robert Henry Parker (2014), Accounting History from The Renaissance to The Present: A remembrance of Luca Pacioli, Routledge.

Lowe, D. Jordan, James L. Bierstaker, Diane J. Janvrin, and J. Gregory Jenkins (2017), "Information Technology in an Audit Context: Have the Big 4 Lost Their Advantage?", Journal of Information Systems, Vol. 32, No. 1: 87-107.

Lumpkin, G. Tom, and Gregory G. Dess (1996), "Clarifying the Entrepreneurial Orientation Construct and Linking It to Performance", The Academy of Management Review, Vol. 21, No. 1: 135. doi:10.2307/258632

Miller, Danny (1983), "The Correlates of Entrepreneurship in Three Types of Firms", Management Science, No. 29: 770791.

Özdoğan, Burak (2017), "The Future of Accounting Profession in an Era of Start-Ups", (Ed. Soner Gokten), Accounting and Corporate Reporting, IntechOpen, DOI: 10.5772/intechopen.69264

Özdoğan, Burak (2018), Bugün Girişimcilik, İstanbul: Abaküs Yayınları.

Rauch Andreas., Frese Michael (2008), "Entrepreneurial Orientation”, (Ed: Bausch A., Schwenker B.), Handbook Utility Management, Springer, Berlin.

Rauch, Andreas, Johan Wiklund, George T. Lumpkin, and Michael Frese (2009), "Entrepreneurial Orientation and Business Performance: An Assessment of Past Research and Suggestions for the Future", Entrepreneurship Theory and Practice, Vol. 33, No. 3: 761-787. 


\section{Eskişehir Osmangazi Üniversitesi iiBF Dergisi}

Robinson, Peter B., David V. Stimpson, Jonathan C. Huefner, and H. Keith Hunt (1991), "An Attitude Approach to the Prediction of Entrepreneurship", Entrepreneurship Theory and Practice, Vol. 15, No: 4: 13-32.

Scott, William R. (1997), Financial Accounting Theory, Vol. 3, Upper Saddle River, NJ: Prentice Hall.

Shih-Yi Chien (2014), "Franchisor Resources, Spousal Resources, Entrepreneurial Orientation, and Performance in a Couple-owned Franchise Outlet", Management Decision, Vol. 52 No. 5: 916 - 933.

Tysiac, Ken, and Jeff Drew (2018), “Accounting Firms: The Next Generation; Command of Data Will Take Precedence as Advanced Technologies Push CPAs to Seek New Skills, Explore Different Services, and Enter into New Practice Structures", Journal of Accountancy, Vol. 225, No. 5: 26.

Wiklund, Johan, and Dean Shepherd (2003), "Knowledge-based Resources, Entrepreneurial Orientation, and the Performance of Small and Medium-sized Businesses", Strategic Management Journal, Vol. 24, No. 13: 1307-1314. 


\section{Extended Summary}

\section{Research of Individual Entrepreneurial Orientation of Accounting Professionals In Turkey}

With the driving force of technological advances, a new generation of digital accounting initiatives is being established, and many of these new generation initiatives are not established by Professional accountants, but by technology entrepreneurs who have no expertise in the field of accounting. At this point, the individual entrepreneurial orientation of accounting professionals may provide important insights about their ability to adapt to future business models as a critical indicator. The strong individual entrepreneurial orientation of professional accountants will enable them to meet the expectations for the future of the profession and to survive in the competitive environment in which entrepreneurs will be involved. In this paper, the individual entrepreneurial orientation and entrepreneurial intentions of the accounting professionals in Turkey were investigated.

In this context, the following research problems are defined:

- Are the individual entrepreneurial orientations of accounting professionals high?

- Do demographic variables affect the individual entrepreneurial orientation levels of accounting professionals?

- Is there a difference between the individual entrepreneurial orientation levels of accounting professionals who intend to be entrepreneurs and those who do not have such a desire?

Entrepreneurial Orientation is defined as "the processes, practices and decision-making activities that lead to a new venture" by Lumpkin and Dess (1996:136). Entrepreneurial Orientation consists of these five components for corporate structures: innovation, proactivity and risk-taking, autonomy and competitive aggression (Miller, 1983; Covin and Slevin, 1986). Previous literature has shown that Entrepreneurial Orientation and business performance are positively related (Lumpkin and Dess, 1996; Wiklund and Shepherd 2003; Rauch and Frese, 2009). Therefore, the Entrepreneurial Orientation has been recognized as an important indicator of the results of the entrepreneurial activities of enterprises (Covin and Slevin, 1991). Just like in institutions, a high Entrepreneurial Orientation in individuals may mean that people are more open to innovation, which will increase the level of preparedness for the future. Bolton and Lane (2012) argue that having a strong Individual Entrepreneurial Orientation will lead people to entrepreneurship.

In the context of the literature discussed, 7 hypotheses were developed to be tested in this study. The hypotheses developed are as follows:

- H1a: Accounting professionals have a high Individual Entrepreneurial Orientation.

- $\quad \mathrm{H} 1 \mathrm{~b}$ : There is a difference between the Individual Entrepreneurial Orientations of the male and female accounting professionals.

- H1c: There is a difference between the individual entrepreneurial orientations of accounting professionals with a CPA firm and working in other institutions.

- $\quad \mathrm{H} 1 \mathrm{~d}$ : There is a difference between the individual entrepreneurial orientation of accounting professionals under 30 and over 30 in terms of age groups.

- $\quad \mathrm{H} 1 \mathrm{e}$ : There is a difference between the individual entrepreneurial orientation of those who are in the internship phase and the accounting professionals who have CPA certificates.

- H1f: There is a difference between the individual entrepreneurial orientations of the accounting professionals who have an undergraduate and graduate degree.

- $\quad \mathrm{H} 1 \mathrm{~g}$ : There is a difference between the individual entrepreneurial orientation of accounting professionals with a high intention of becoming an entrepreneur and no-intention.

To answer research questions and to test hypotheses, the survey method was used in this study. The questionnaire is based on the Individual Entrepreneurial Orientation scale developed by Bolton \& Lane (2012). The scale consists of three dimensions: innovation, risk and proactivity. The universe of research is formed by members of the accounting profession working in Turkey. The LinkedIn social platform has been used to deliver the questionnaire. 516 questionnaires were answered through the platform, of which 393 were included in the analysis. Of the participants included in the analysis, 163 (41.5\%) were female and 230 (58.5\%) were male. The age group of participants varies between 18 and 60 years old, but $90 \%$ are participants under 45 years of age. Nearly all participants $(99.5 \%)$ have a minimum level of undergraduate education. $26.9 \%$ of the survey participants were in the CPA internship phase, while $73.1 \%$ were members of the profession with a CPA certificate. $47.8 \%$ of the participants had more than 10 years of experience, while those with less than 5 years of experience represented $23.4 \%$. 


\section{Eskişehir Osmangazi Üniversitesi iiBF Dergisi}

According to the results of the analysis, it is determined that the individual entrepreneurial orientation of accounting professionals in Turkey was high. Proactivity has been determined as the dimension with the relatively lowest score in three dimensions. Therefore, the development of the proactive characteristics required by this dimension of the accounting professionals will allow for an increase in the individual entrepreneurial orientation. On the other hand; it has been demonstrated by hypothesis tests that demographic variables such as age, gender, and educational status do not significantly affect the entrepreneurial orientation of the accounting professionals. Besides, the individual entrepreneurial orientation of professionals with the high intention of becoming an entrepreneur has been measured as high, excluding the risk dimension. As a reason for the relatively low-risk dimension, it can be said that due to the nature of the accounting profession, its members tend to avoid/avoid risk. The research results show that; accounting professionals in Turkey have characteristics that can play an active role in the future of the profession and evaluate possible business opportunities with high individual entrepreneurial orientation and high entrepreneurial intentions. 